
SUSUNAN DEWAN REDAKSI

“JURNAL NASIONAL KOMPUTASI DAN TEKNOLOGI INFORMASI (JNKTI)"

\author{
Penanggung Jawab \\ Muhammad Fadhli, S.Kom, M.Kom \\ Ketua Dewan Editor \\ Zulfan, ST, MT \\ Editor Pelaksana \\ Munawir, ST, MT \\ Baihaqi, ST, MT \\ Sekretaris \\ Yeni Yanti, ST, MT \\ Mitra Bestari \\ Prof. Dr. Ir. Yuwaldi Away, M.Sc \\ Dr. Taufiq A. Gani, S.Kom, M.Eng.Sc \\ Dr. Melinda, ST, M.Sc \\ Layout \\ Eka Novendra, ST \\ Penerbit \\ Program Studi Teknik Informatika \\ Universitas Serambi Mekkah \\ Alamat Penerbit
}

Gedung H Fakultas Teknik Universitas Serambi Mekkah

Jl. T. Imum Lueng Bata, Telp. (0651)26160 Batoh - Banda Aceh 


\section{SINOPSIS}

Jurnal Nasional Komputasi dan Teknologi Informasi (JNKTI) merupakan jurnal ilmiah nasional yang diterbitkan oleh Program Studi Teknik Informatika Universitas Serambi Mekkah yang mempublikasikan artikel-artikel ilmiah dalam bidang komputasi dan teknologi informasi.Jurnal ini terbit sebanyak 2 (dua) kali dalam 1 (satu) tahun yaitu pada Bulan April dan Oktober. Bidang-bidang fokus penelitian yang akan dipublikasi dalam jurnal ini antara lain :

- Bidang Rekayasa Perangkat Lunak

- Bidang Jaringan Komputer

- Bidang Multimedia dan Pengolahan Citra Digital

- Bidang Komputasi

- Multidisiplin ilmu lainnya yang relevan 
DAFTAR ISI

JNKTI VOL.2 NO.1, APRIL 2019

Studi Simulasi Aerodinamika Airfoil dan Prediksi

$1-8$

Performa Picth Tetap Turbin Angin Poros Tegak (Darrieus)

terhadap Output Power untuk Aplikasi Kecepatan Angin Rendah

Wahyu Priyanto ${ }^{1}$, Ira Devi Sara ${ }^{2}$, Rakhmad Syafutra Lubis ${ }^{3}$

Analisis Performansi Video Streaming Dengan Menggunakan

$9-12$

Protokol RTSP Pada Jaringan IEEE 802.11n

Rahmad Rizki ${ }^{1}$, Rizal Munadi ${ }^{2}$, Syahrial $^{2}$

Pengaruh Heatsink Terhadap Kinerja Modul Surya

$13-18$

T. Mizan Sya'rani D. ${ }^{1 *}$, Ira Devi Sara ${ }^{2}$, dan Laina Hilma Sari ${ }^{3}$

Penentuan Tingkat Penyebaran Ikan Berdasarkan Citra

Suhu Permukaan Laut Di Perairan Laut Kabupaten Aceh Jaya

Menggunakan Satelit Aqua Modis

Naziran ${ }^{1}$, Rizal Munadi ${ }^{2}$, Muchlisin ${ }^{2}$

Studi Pengaruh Hibridisasi Seleksi Roullete Wheel Dengan $26-30$

Tournament Selection Menggunakan Algoritma Berevolusi Pada TSP

Cut lilis Setiawati ${ }^{1}$, Taufiq Abdul Gani ${ }^{2}$, Yuwaldi Away ${ }^{2}$

Audit Dan Optimasi Energi Listrik Pada Bangunan Kampus $31-37$

Menggunakan Metode Algoritma Genetika

Samsuddin $^{1}$, Suriadi ${ }^{2}$, Yuwaldi Away ${ }^{3}$

Aplikasi Histogram Discrete Cosine Transform (DCT) Untuk $38-42$

Sistem Temu Kembali Citra Termal Berbasis Konten

Faridah $^{1}$, Khairul Munadi ${ }^{2}$, Fitri Arnia ${ }^{3}$

Pengujian Algoritma Artificial Neural Network (ANN) $43-47$

Untuk Prediksi Kecepatan Angin

Syukri $^{1}$, Samsuddin ${ }^{2}$

Penerapan Information Retrieval Menggunakan Pemodelan $48-54$

Topik Pada Deskripsi Portal Multimedia

Indra Gita Anugrah ${ }^{1}$ dan Harunur Rosyid ${ }^{2}$

Analisa Steganografi untuk Citra Bewarna (RGB)

Menggunakan Metode Less Significant Bit (LSB)

Raihan Islamadina $^{1}$, Baihaqi $^{2}$, dan Mauzar sulistriadi ${ }^{3}$ 


\title{
Analisis Performansi Video Streaming Dengan Menggunakan Protokol RTSP Pada Jaringan IEEE 802.11n
}

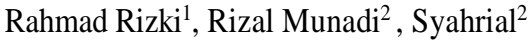 \\ ${ }^{1}$ Magister Teknik Elektro, Universitas Syiah Kuala \\ ${ }^{2}$ Program Studi Teknik Elekro dan Komputer \\ Fakultas Teknik Universitas Syiah Kuala \\ *Koresponden email: rahmadrizki@gmail.com
}

\begin{abstract}
Abstrak - Dalam mewujudkan komunikasi yang handal pada layanan streaming dengan tingkat realibility dan availability yang terjaga maka dibutuhkan performansi jaringan yang baik. Artinya sebuah jaringan harus mampu menjaga tingkat utilitasnya dalam keadaan optimal dalam kondisi apapun. Apabila kualitas sudah sangat baik maka penggunaan video streaming akan semakin digunakan oleh penggunanya. Dengan teknologi streaming, banyak sekali manfaat yang bisa didapatkan. Murah, karena hanya memerlukan satu server yang bisa digunakan untuk banyak user. Untuk menjalankan streaming tersebut bisa dihubungkan beberapa user dalam satu jaringan. Akan lebih efisien lagi apabila dalam membuat jaringan yang bersifat wireless ketimbang wired. Dengan wireless, bisa lebih menghemat dalam pengadaan kabel. Selain itu juga lebih mudah dalam melakukan konfigurasi pada jaringan. Salah satu kegunaan dari teknologi video streaming yang banyak digunakan dalam kegiatan sehari hari yaitu Video Conference. Teknologi multimedia yang satu ini memang sangat bergantung dari kualitas jaringan yang tersedia. Dibutuhkan hubungan yang handal antar user satu dengan yang lain sehingga membuat teknologi ini memerlukan protokol pendukung yang tepat. Salah satu prokotol yang digunakan untuk pertukaran data secara streaming adalah Real Time Streaming Protokol (RTSP). RTSP merupakan protokol aplikasi untuk kendali pengiriman data yang memiliki karakteristik realtime seperti streaming media. RTSP sering juga disebut sebagai remote control jaringan untuk streamin server. Tujuan dari penelitian ini adalah untuk melihat besarnya pengaruh variasi codec, jarak, dan power transmisi pada paket data multimedia dalam jaringan IEEE 802.11n pada protokol RTSP. Berdasarkan hasil penelitian, maka dapat di ambil kesimpulan bahwa Pada pengukuran delay dari ketiga skenario penggunaan layanan diperoleh nilai delay tertinggi pada saat pengujian adalah sebesar 0,007 s untuk codec H.264 dengan kondisi Power Transmisi $1 \mathrm{dbm}$ dengan jarak 1 meter sementara nilai delay terendah adalah sebesar 0,002 s pada jarak 1 meter dan power transmisi $1 \mathrm{dbm}$.
\end{abstract}

Kata kunci : Video streaming, Protokol, Wireless LAN, Real Team Streaming Protokol (RTSP)

\section{Pendahuluan}

Berbagai layanan hiburan tersedia secara berbayar dan gratis, baik yang ditawarkan oleh penyedia jasa televisi maupun hiburan yang dapat diakses dengan jaringan internet. Salah satu teknologi yang sedang tren saat ini yang tersedia pada jaringan internet adalah teknologi video streaming. Streaming adalah salah satu layanan multimedia yang mampu menawarkan sebuah servis yang cukup memadai bagi penggunanya untuk menikmati layanan multimedia secara real-time dan tingkat kestabilan yang terjaga.

Dengan teknologi streaming, banyak sekali manfaat yang bisa didapatkan. Murah, karena hanya memerlukan satu server yang bisa digunakan untuk banyak user. Untuk menjalankan streaming tersebut bisa dihubungkan beberapa user dalam satu jaringan. Akan lebih efisien lagi apabila dalam membuat jaringan yang bersifat wireless ketimbang wired. Dengan wireless, bisa lebih menghemat dalam pengadaan kabel. Selain itu juga lebih mudah dalam melakukan konfigurasi pada jaringan.

Salah satu prokotol yang digunakan untuk pertukaran data secara streaming adalah Real Time Streaming Protokol (RTSP). RTSP bukan protokol pengiriman data aktual berupa streaming audio maupun video, melainkan protokol kendali streaming media [1]. RTSP merupakan protokol aplikasi untuk kendali pengiriman data yang memiliki karakteristik real-time seperti streaming media. RTSP sering juga disebut sebagai remote control jaringan untuk streamin server. Dengan menggunakan protokol RTSP antara client dan video streaming server bisa mengirimkan permintaan ketika terjadi interaksi, RTSP mempunyai kemampuan untuk mempertahankan keadaan dari sebuah sesi (mempertahankan hubungan antara video streaming server dan client secara konsisten), sedangkan protokol HTTP tidak bisa. RTSP mendukung penggunaan dari RTP sebagai dasar protokol pengiriman data. Protokol tersebut diharapkan bisa memberikan cara pemilihan jalur pengiriman yang optimum kepada client. [2].

Teknologi Wireleess LAN saat ini mayoritas menggunakan standar IEEE $802.11 \mathrm{a} / \mathrm{b} / \mathrm{g} / \mathrm{n}$ [3]. Standar yang akan digunakan dalam penelitian ini adalah 802.11n. Standar 802.11n merupakan standar perubahan yang dilakukan untuk jaringan W-LAN agar dapat meningkatkan throughput melebihi standar $802.11 \mathrm{~b}$ dan $802.11 \mathrm{~g}$. Pada standar ini, data rate maksimum dalam lapisan fisik OSI (PHY) 
ditingkatkan dari 54 Mbps menjadi 600 Mbps dengan menggunakan empat ruang aliran pada bandwith $40 \mathrm{MHz}$. Untuk dapat memberikan layanan yang memuaskan kepada pengguna, maka kinerja jaringan wireless LAN 802.11n harus berada pada kondisi yang baik. Kinerja jaringan video streaming dikatakan baik apabila nilai delay, packet loss dan data rate memenuhi standar berdasarkan ITU-T G1010.

Berdasarkan latar belakang, maka penelitian ini bertujuan untuk melihat besarnya pengaruh variasi codec, jarak, dan power transmisi pada paket data multimedia dalam jaringan IEEE $802.11 \mathrm{n}$ pada protokol RTSP dan untuk menganalisis performansi protokol RTSP pada paket data multimedia dengan menggunakan jaringan IEEE 802.11n.

\section{Tinjauan Pustaka}

Streaming merupakan sebuah metode untuk membuat audio, video, dan multimedia yang lain yang tersedia untuk real-time pada tipe jaringan yang berbeda [4]. Pada aplikasi video streaming masalah yang ada bertambah dengan adanya proses capturing dan live decoding pada sisi server. Selain masalah pada server, masalah terbesar yang dihadapi dari teknologi ini adalah keterbatasan bandwidth sedangkan proses komunikasi menggunakan digital video ini menghabiskan resource yang cukup besar. Semakin besar bandwidth yang tersedia, semakin bagus kualitas video yang ditampilkan. Aplikasi streaming media yang membutuhkan bitrate cukup tinggi menyebabkan beban jaringan bertambah sehingga menyebabkan service yang diberikan tidak dapat berjalan dengan baik.

Protokol memainkan peran penting dalam streaming video. Ada berbagai protokol yang tersedia untuk komunikasi data tetapi protokol yang paling umum digunakan untuk streaming video termasuk Hypertext Transfer Protocol (HTTP) dan Real Time Streaming Protocol (RTSP) [5]. Protokol adalah sekumpulan perintah atau sistem yang mengatur proses komunikasi, transmisi dan penerimaan informasi, pembacaan pesan serta pengkoordinasian semua komputer yang terintegrasi dalam jaringan, sehingga dapat melakukan aktifitas-aktifitas tersebut dengan lancar.

RTSP adalah singkatan dari Real Time Streaming Protocol yang merupakan bagian dari protokol jaringan yang dirancang untuk digunakan dalam kondisi multimedia dan sistem komunikasi untuk mengendalikan server aliran media (media streaming). Protokol ini digunakan untuk menetapkan dan mengendalikan sesi media antara dua titik ujungnya [4].

Multicast dapat diilustrasikan dengan alamat Internet Protocol (IP) yang dipergunakan untuk pengiriman paket data dari satu pengirim ke beberapa penerima (receiver) dalam satu jaringan atau disebut dengan one-to-many. Receiver tersebut dari berbagai jaringan yang berbeda yang terhubung melalui sebuah router. Oleh sebab itu alamat Internet Protocol (IP) receiver dikelompokkan pada suatu grup tertentu sehingga menjadi lebih efisien.

Wireless Local Area Network (WLAN) merupakan suatu sistem telekomunikasi yang dapat digunakan sebagai jaringan wireless. Dengan penggunaan teknologi frekuensi radio, wireless LAN pengiriman data dan penerimaan melalui transmisi gelombang radio. Saat ini peralatan Wireless LAN mengadopsi standar Institute of Electrical and Electronics Engineers (IEEE) 802.11 telah didukung oleh banyak vendor yang membuat perangkat seperti PDA, notebook, ponsel dan lain-lain. Dari standar ini masih ada beberapa standar lagi yang dipakai untuk membedakan kecepatan koneksi ataupun teknologi dan frekuensi yang dipakai, seperti 802.11b mampu mentransfer data sampai $11 \mathrm{Mbps,} 802.11 \mathrm{a}$ dan $802.11 \mathrm{~g}$ yang mampu mentransmisikan data sampai 54 Mbps.

\section{Metode Penelitian}

Metodologi penelitian yang digunakan adalah eksperimental dengan penggunaan perangkat Lunak VLC Media Player dan perangkat keras Mikrotik hAP AC Lite. Yang diteliti pada penelitian ini adalah Performansi transmisi video streaming format H.264, H.265 dan MPEG-4 pada WLAN IEEE 802.11n dengan menggunakan protokol RTSP untuk melihat pengaruh kualitas layanan parameter QoS delay, packet loss dan throughput. Tahapan penelitian diperlihatkan pada gambar 1 .

\subsection{Konfigurasi Peralatan Jaringan}

Kondisi wireless rauter pada saat konfigurasi ini adalah default dengan IP 192.168.1.254 dan DHCP enable, kemudian pada saat konfigurasi wireless router mode yang digunakan adalah 802.11n. Pada sisi server, IP yang akan dicreate adalah 192.168.1.103 sedangkan pada sisi client atau user IP address didapatkan secara DHCP sehingga tidak perlu konfigurasi. Untuk lebih jelas bisa dilihat pada Gambar 2.

\subsection{Data pengujian}

Pada penelitian ini data yang diuji adalah video dengan format MPEG-4, H.264 dan H.265 untuk menguji performasi transmisi dengan menggunakan protokol RTSP pada Wireless LAN 802.11n, dan mendapatkan hasil parameter QoS Delay, paket loss dan throughput.

\subsection{Teknik yang digunakan}

Teknik yang digunakan pada penelitian ini adalah eksperimental. Pada Pengujian ini melihat kualitas jaringan dengan cara streaming pada paket data multimedia dengan menggunakan protokol RTSP. Teknik yang digunakan yaitu server mengirimkan ke client melalui access point (AP) suatu data yaitu streaming video dengan menggunakan software VideoLan Client yang telah dikonfigurasi. 


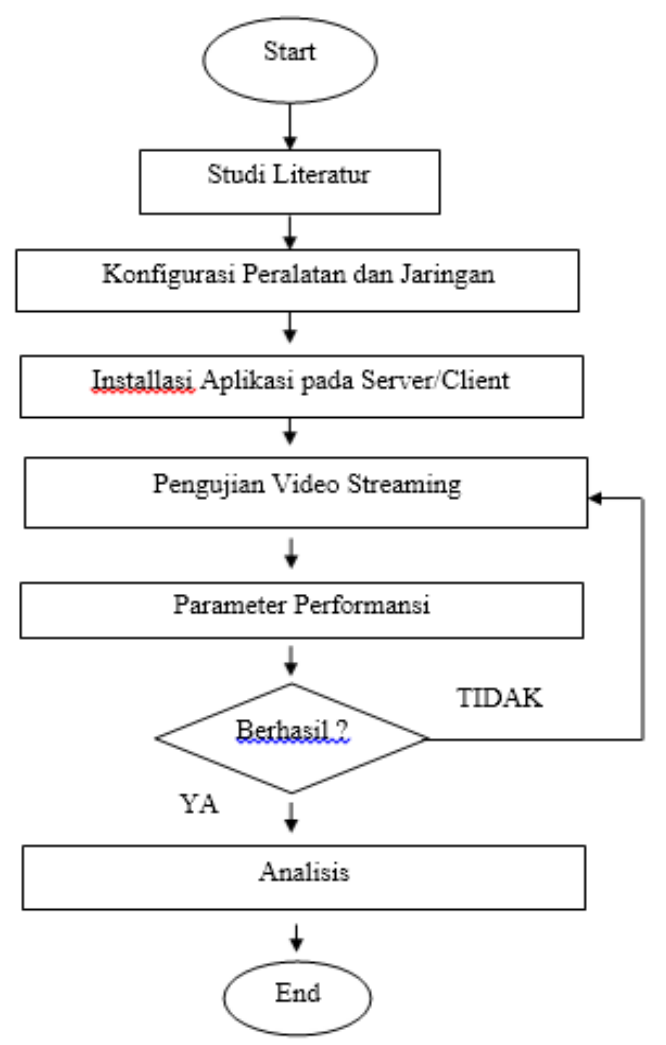

Gambar 1. Metode penelitian

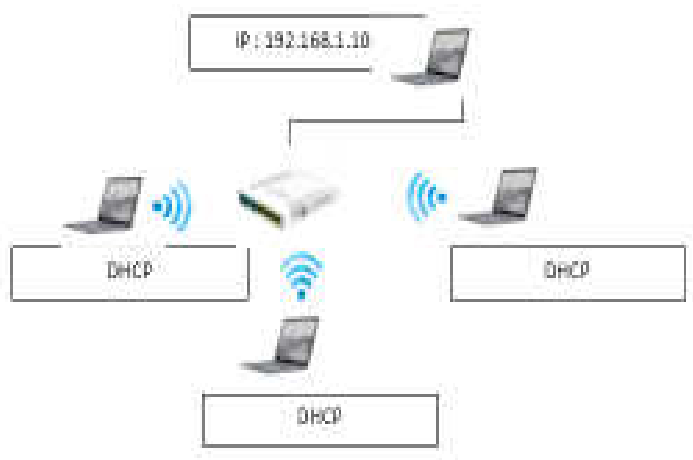

Gambar 2. Konfigurasi peralatan jaringan

Video yang dikirimkan sebesar 295 MB degan format sumber H.265. Di router di setting Multicast Routing PIM-SM aktif dengan destinasi IP Multicast 224.1.2.3.

Pengambilan data QoS seperti packet loss, delay dan throughput sebanyak 10 kali dengan waktu yang berbeda dimulai dari 120 second. Pada posisi client dipasang software yaitu VideoLan Client (VLC) dan Wireshark yang telah terkonfigurasi. Pada penelitian ini Teknik pengiriman data yang digunakan adalah multicast dimana data yang sama tidak melalui link jaringan yang sama lebih dari sekali, sehingga transmisi data cepat dan efisien. Untuk lebih jelas dapat dilihat pada gambar 3 .

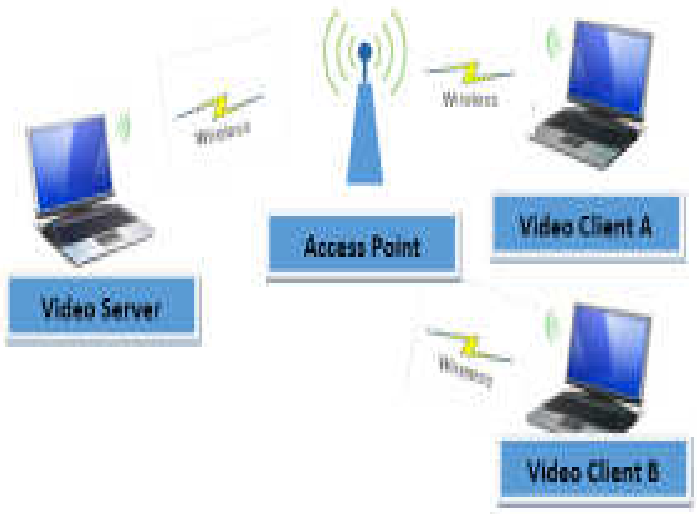

Gambar 3. Teknik multicast

\section{Hasil Dan Pembahasan}

\subsection{Hasil pengujian dengan protokol RTSP}

Pada pengujian data video format video format H.264, H.265 dan MPEG-4 dengan protokol RTSP dengan jarak 1 meter, Power transmisi $=1 \mathrm{dbm}$, bandwidth 1 Mbps dapat dijelaskan pada tabel berikut. Untuk lebih jelasnya bisa dilihat pada tabel 1.

Tabel 1. Hasil pengujian dengan protokol RTSP

\begin{tabular}{|c|l|c|c|c|}
\hline No. & $\begin{array}{c}\text { Format } \\
\text { Video }\end{array}$ & $\begin{array}{c}\text { Delay } \\
\text { (Second) }\end{array}$ & $\begin{array}{c}\text { Paket Loss } \\
(\%)\end{array}$ & $\begin{array}{c}\text { Throughput } \\
\text { Mbps }\end{array}$ \\
\hline 1 & H.264 & 0,007 & 2,5 & 0,126 \\
\hline 2 & H.265 & 0,002 & 0,8 & 0,493 \\
\hline 3 & MPEG-4 & 0,006 & 0,2 & 0,145 \\
\hline
\end{tabular}

Berdasarkan tabel 1. dapat dijelaskan bahwa ratarata delay lebih bagus dengan paket video H.265, sedangkan paket loss untuk H.264 paling tinggi yatiu 2,5 dan untuk throughput memiliki nilai H.265 lebih tinggi dibandingkan dengan MPEG-4 dan H.264. Hasil testbed dapat dilihat di gambar 4. 

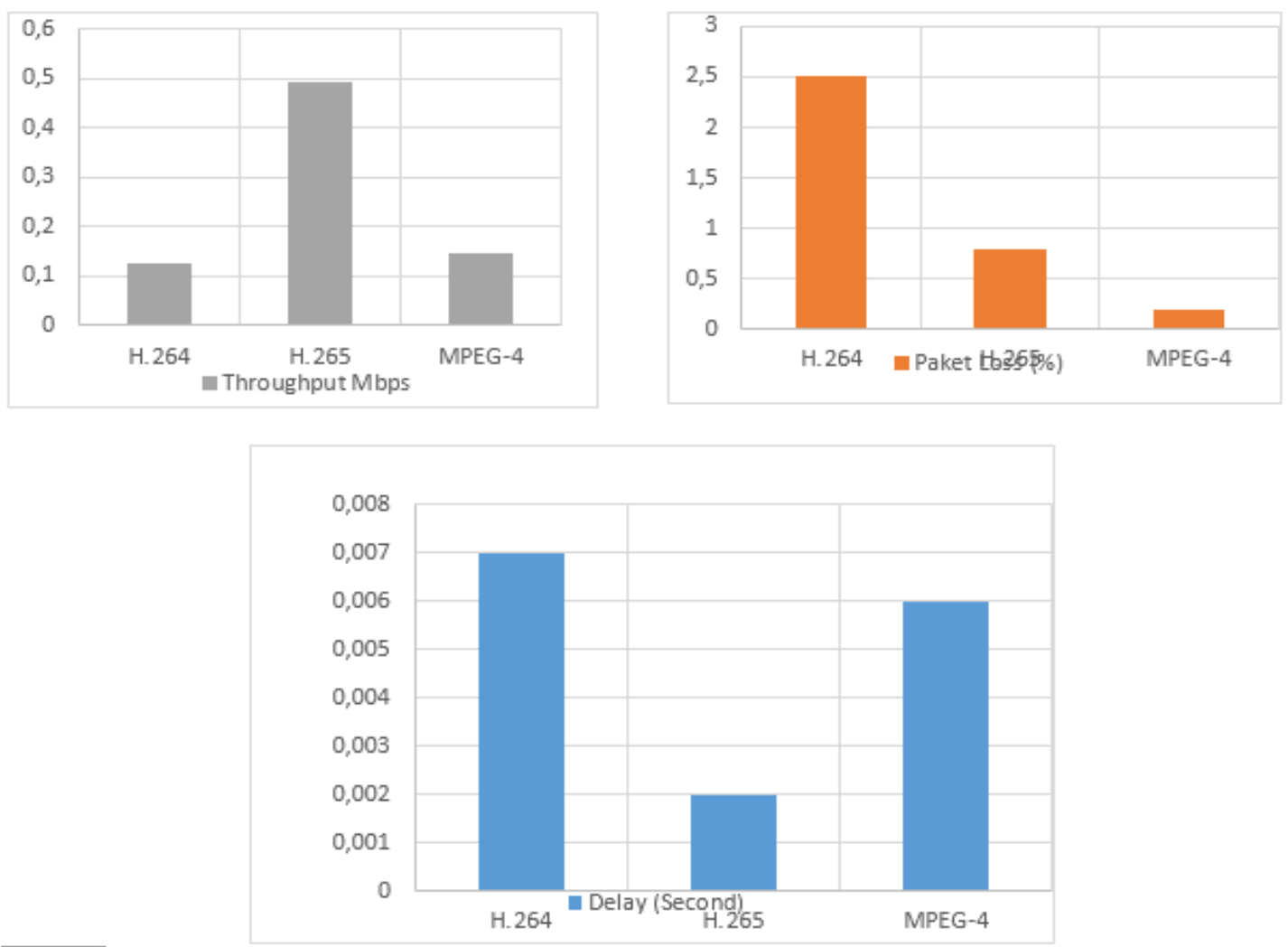

Gambar 4. Pengaruh thoughput, packet loss dan juga Delay.

\section{Kesimpulan Dan Saran}

Berdasarkan hasil pengujian dapat diambil beberapa kesimpulan yaitu sistem layanan video streaming berhasil menampilkan video hasil streaming dari server, baik pada layanan video streaming untuk codec MPEG-4, H. 264, dan H.265 memenuhi standar ITU-T G.1010 dan G.114.

Pada pengukuran delay dari ketiga skenario penggunaan layanan diperoleh nilai delay tertinggi pada saat pengujian adalah sebesar 0,007 s untuk codec H.264 dengan kondisi Power Transmisi $1 \mathrm{dbm}$ dengan jarak 1 meter sementara nilai delay terendah adalah sebesar $0,002 \mathrm{~s}$ pada jarak 1 meter dan power transmisi $1 \mathrm{dbm}$. Pada pengukuran delay pada penggunaan layanan dengan perubahan codec terlihat bahwa ada perubahan nilai delay.

\section{Daftar Pustaka}

[1].Chaidir, I., \& Haryanto, T. B. (2018). Rancangan Bangun Video Streaming Menggunakan RED5 Sebagai Media Server Berbasis Protokol RTSP. Jurnal Ilmu Pengetahuan dan Teknologi Komputer, 4(1), 49-54.

[2].Afaq, iqbal, “Analyzing Impact of Video Codec, Encapsulation Methods and Streaming Protocols on the Quality of Video Streaming”. 978-1-47990615-4/13/\$31.00 @2013 IEEE, April, 2013

[3].V.A.B Harto, R.Primananda, A. Suharsono"Analisis Performansi H.264 dan H.265 pada Video Streaming dari Segi Quality Of
Service" Jurnal Pengembangan Teknologi Informasi dan Ilmu Komputer Vol. 1, No. 10, Oktober 2017

[4].A.I Diwi, R Rumani M , I Wahidah "Analisis Kualitas Layanan Video Live Streaming pada Jaringan Lokal Universitas Telkom Quality of Service Analysis for Live Streaming Video Services on Telkom University Local Network" Buletin Pos dan Telekomunikasi, Vol.12 ,No.3, September 2014

[5].Y. Christyono, I. Santoso, and A. Zahra "Perancangan Dan Pengukuran Kinerja Video Streaming Menggunakan Red5 Pada Mesin Virtual". Jurnal Transmisi, 19, (3), Juli 2017

[6]. Faisal F, Munadi R, Syahrial S. Analisis Perbandingan Performansi Transmisi Video Dengan Unicast Pada Wlan Ieee 802.11 ac. Jurnal Nasional Komputasi dan Teknologi Informasi (JNKTI),1(2), Oktober 2018.

[7]. Yanti Y, Pramita N, Maulizar M. Analisa Pengukuran Interferensi Pada Acces Point (Ap) Untuk Mengetahui Kualitas Quality of Service (Qos). Jurnal Nasional Komputasi dan Teknologi Informasi (JNKTI), 1(1), April 2018. 
